\title{
Two-layer soil covers on selected radioactive waste rock dumps at Wismut: results of more than ten years of hydrological monitoring
}

\author{
A. Schramm Department Water Management, Wismut GmbH, Germany \\ M. Roscher Department Mine Remediation/Geotechnics, Wismut GmbH, Germany
}

\begin{abstract}
In East Germany, uranium mining and milling by the Soviet-German Wismut Company lasted from 1946 to 1990. The Wismut uranium mining area consists of numerous waste rock dumps (WRDs) in Saxony and Thuringia. The waste rock is classified as radioactive and it is partially susceptible to acid rock drainage. The different cover systems obstruct direct contact with radioactive waste rock, prevent dust and limit radon emission and oxygen ingress. In contrast to the cover system of WRD Beerwalde in Thuringia, the systems at the Schlema site in Saxony were not designed to control the percolation rate but to limit the radon emission. The Schlema region experiences an average mountain climate, with a mean annual precipitation of $890 \mathrm{~mm}$ (range: 590-1340 mm). The climate at WRD Beerwalde can be characterised as moderately humid, with a mean annual precipitation of $715 \mathrm{~mm}$ (range: 452-1086 $\mathrm{mm}$ ).

The cover of the dumps at the Schlema site, located very close to residential areas, consists of a moderately compacted storage layer $(0.8 \mathrm{~m}$ mineral soil made of sandy silt) and a $0.2 \mathrm{~m}$ thick organic vegetation layer. The major part of the WRD Beerwalde is covered by a two-layer cover consisting of a $1.5 \mathrm{~m}$ thick storage layer underlain by a $0.4 \mathrm{~m}$ thick compacted sealing layer made of clayey loam.

This paper presents the case studies of WRD Borbachdamm and WRD 366 at the Schlema site, covered in 2000 and 2004, and the WRD Beerwalde covered and afforested until the end of 2002. Local soil hydrological monitoring systems were installed immediately after cover construction to measure the daily water balance components. Each measurement system consists of lysimeters to record the amount of seepage as well as various soil probes (tensiometer/equitensiometers, soil moisture meters) to record the dynamics of soil water in the cover. The results show the water balance development of the soil covers, with time as a function of plant growth and exposition. Percolation rates of about 26-34\% of annual precipitation at the Schlema site and of 2-20\% at the Beerwalde site were observed. An obvious rise of tension as a consequence of an increasing water demand of plants was noted several years after first seeding. Furthermore, there was a rising difference between minimum and maximum soil moisture during the growing season due to a denser vegetation cover.

The daily water balances were modelled annually, calibrated with the measured data and checked against the annual amount of seepage. The modelling results at the Schlema site show the expected change of the hydrological balance, with actual evapotranspiration increasing from 300 to $600 \mathrm{~mm} /$ year and percolation decreasing from 500 to $250 \mathrm{~mm} /$ year. In contrast to the WRDs at the Schlema sites, the annual percolation rates at WRD Beerwalde have increased due to rising evapotranspiration rates strongly affected by exposition. The paper concludes with a discussion of the functionality of the various cover systems at the different sites over time with regard to influences of vegetation type, plant growth and exposition.
\end{abstract}

\section{$1 \quad$ Introduction}

From 1946 through 1990, the SAG/SDAG Wismut Company mined uranium ore in the territories that have become the new federal states of Saxony and Thuringia of the reunited Germany. By the end of 1990, a total of about 216,000 tonnes of uranium had been produced at a number of sites in the southern part of East Germany. In addition to plant areas, mine units, a residual open pit and mill tailings, the legacies included more than 300 million $\mathrm{m}^{3}$ of waste rock material. In 1991, Wismut $\mathrm{GmbH}$, being the successor 
company to SDAG Wismut and restructured as a federally owned company, started to remediate the legacies left behind by those uranium mining operations in Saxony and Thuringia.

One ambitious task of WISMUT is to remediate numerous WRDs due to their local conditions. Covering of WRDs has to meet several criteria. Among other goals, cover systems have to control direct radiation/emission, control/minimise percolation through the cover and offer good conditions for projected vegetation type. The applied cover systems were authorised in most cases with restrictions. Defined and approved environmental surveillance during and after remediation activities is performed for the dumps to monitor contaminant release via the aquatic pathway and radon emission via the atmospheric pathway. In addition to demonstrating compliance with emission levels and regulatory standards, focus is also placed on providing evidence of successful remediation. Hydrological measurements are conducted in addition to mandatory environmental monitoring in order to quantify percolation through the cover, to observe vegetation development and to understand soil water dynamics as well as determine long-term water balances (Löser et al., 2011). The paper presents hydrological studies performed on three waste rock dumps (WRDs) at different mining sites of WISMUT covered with several two-layer covers. These investigations provide a range of percolation under different weather conditions measured over a long period. The results underline the importance to water balance of cover material and thickness and of the particular type and growth stage of vegetation cover. The paper is based on more than 10 years of detailed hydrological measurements and an attendant model application for covered WRDs, which are unique to this extent for covered WRDs in Germany.

\subsection{General site characteristics}

At the Schlema site in Saxony (Ore Mountains), there were 37 WRDs with a total volume of about 45 million $\mathrm{m}^{3}$. In Schlema, which has regained its status as a spa town, in situ remediation of the majority of the WRDs started in 1992. At the Ronneburg site in Thuringia, no less than 12 WRDs were excavated and relocated to the Lichtenberg residual open pit (125 million $\mathrm{m}^{3}$ ) during 1991-2008. Moreover, relocation and banking up of the WRDs Drosen and Korbußen at the Beerwalde mine dump site created a WRD of 8.8 million $\mathrm{m}^{3}$ that was remediated in situ. With a view to ensuring stability, WRD remediation at both sites involved slope flattening/reshaping, covering the dump surfaces according to their respective hazard potential as well as their dump-specific vegetation.

The sites in question were the WRD Borbachdamm and WRD 366 at Schlema as well as the WRD Beerwalde at Ronneburg. These WRDs had been remediated during 2000-04 by the placement of a two-layer cover, which differs in design to meet site-specific boundary conditions and remediation objectives. Unlike the cover system used at WRD Beerwalde in Thuringia, the primary objective of the cover system used at the WRDs Borbachdamm and 366 was not to control the cover percolation rate and thus oxygen ingress but to reduce radon emission. Table 1 characterises the three WRDs discussed. 
Table 1 Characteristics of WRD sites in WISMUT, Germany

\begin{tabular}{cccc}
\hline & WRD Borbachdamm & WRD 366 & WRD Beerwalde \\
\hline Location & Bad Schlema/Saxony & Bad Schlema/Saxony & Ronneburg/Thuringia \\
Altitude m asl & $335-426 \mathrm{~m}$ & $338-468 \mathrm{~m}$ & $318-360 \mathrm{~m}$ \\
Mean precipitation & $890 \mathrm{~mm}$ & $890 \mathrm{~mm}$ & $715 \mathrm{~mm}$ \\
Volume & $1.2 \mathrm{million} \mathrm{m}^{3}$ & 7.5 million $\mathrm{m}^{3}$ & $8.8 \mathrm{millon} \mathrm{m}^{3}$ \\
Footprint & $6 \mathrm{ha}$ & $43 \mathrm{ha}$ & 33.4 ha \\
Slope ratio & $1: 2.5$ & $1: 2.5$ & $1: 3$ \\
Exposition & ENE & WSW & in all directions \\
Cover completion & $1999 / 2000$ & 2004 & 2002 \\
Cover thickness & $1 \mathrm{~m}$ & $1 \mathrm{~m}$ & $1.9 \mathrm{~m}$ \\
Vegetation type & Willow/Grass & Grey Alder/Grass & Grass/Forest \\
\hline
\end{tabular}

\subsection{Cover systems and vegetation of WRDs}

Characterised by a very steep ENE facing slope, the WRD Borbachdamm was piled up with a view to damming the valley location for the storage of uranium ore processing residues. As part of the remedial effort, this slope was flattened to $40 \%$. Work on cover placement on the WRD was completed in 2000 . The mineral soil of $0.8 \mathrm{~m}$ thickness was placed in two interlocking lifts of $0.4 \mathrm{~m}$ each of sandy-loamy silt (Figure 1). The mineral soil has an available volumetric field capacity of about $20 \%$ and an effective hydraulic conductivity of $1 \mathrm{E}-7 \mathrm{~m} / \mathrm{s}$. Permeability slightly decreases with depth. The overlying $0.2 \mathrm{~m}$ thick organic vegetation layer consists of substrate produced by the composting of residual organic materials. Following placement, this substrate was mixed with the mineral soil of the cover. This mixed layer exhibits high hydraulic conductivity (1E-4 m/s) and an available field capacity of about $23 \%$ vol.

Conical in shape, the prominent landscape feature of WRD 366 is a volume of 7.5 million $\mathrm{m}^{3}$, making it one of the largest of its kind at the Schlema site. Remediation of the dump began in 1997, and cover placement was completed in 2004. Design of the $1 \mathrm{~m}$ thick cover is similar to that placed on the WRD Borbachdamm (Figure 1). The mineral soil is of the sandy-loamy silt type with a somewhat lower available volumetric field capacity of $16 \%$. Its effective hydraulic conductivity of $2 \mathrm{E}-7 \mathrm{~m} / \mathrm{s}$ is slightly higher, and the material used for organic vegetation layer is identical to that at the WRD Borbachdamm.

On completion of the cover, the WRDs Borbachdamm and 366 were sown with landscape grass seed, which is a mixture of grasses and herbage (Figure 1). In 2001, a goat willow fascine (Salix caprea) was installed in close vicinity to the soil measuring site (1 $\mathrm{m}$ aside) at WRD Borbachdamm. Within a few years, the fascine had evolved into a hedge. Today the willow trees reach a height of about $5 \mathrm{~m}$. Due to natural succession at WRD 366, grey alders (Alnus incana) were established in 2006 in the area where the soil probes were located. As lush grey alder growth was restricted to a limited section of the measurement area, it allowed attribution of soil probes to either grass or grey alder vegetation until 2012. This was the precondition for a comparison of water balances under grass and grey alder. By the 2012 growing season, the grey alders covered the whole area to the extent that it was no longer possible to differentiate between areas with grass and grey alder vegetation. 
WRD Borbachdamm / WRD 366

\begin{tabular}{|l|l}
\hline $0.2 \mathrm{~m}$ & Organic vegetation layer \\
\hline $0.8 \mathrm{~m}$ & $\begin{array}{l}\text { Storage layer } \\
\text { (sandy-loamy silt) }\end{array}$ \\
\hline & Wast rock material \\
\hline
\end{tabular}

Vegetation WRD Borbachdamm/366:

- landscape grass

$62 \%$ sheeps fescue (Festuca ovina bornito/melord), $25 \%$ red fescue (Festuca rubra reymond/cindy/samanta), $10 \%$ rye grass (Lolium perenne chagall), 3\% herbarge

- WRD Borbachdamm since 2001 goat willow (Salix caprea)

- WRD 366 since 2006 grey alder (Alnus incana)
WRD Beerwalde (two-layer cover)

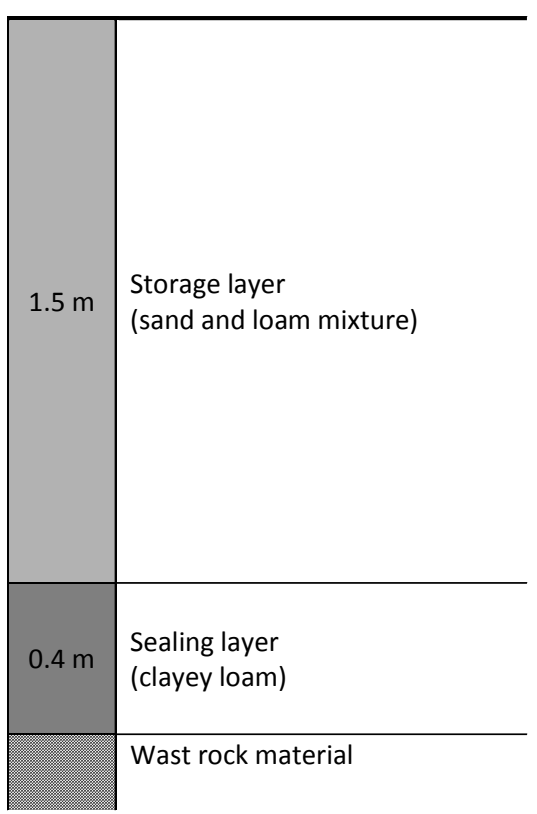

WRD Beerwalde (single-layer cover)

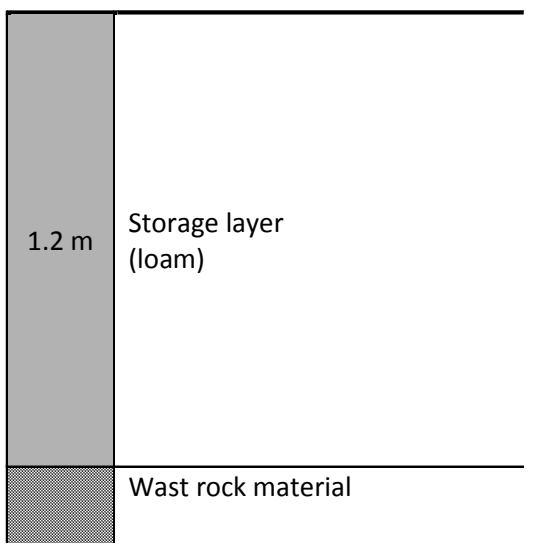

Vegetation WRD Beerwalde:

- landscape grass:

red fescue (Festuca rubra); perennial

rye grass (Lolium perenne)

- ruderal species

- mixed forest (oak, lime, acer, beech, larch, blue spruce, Douglas fir)

\section{Figure 1 Cover systems and vegetation of WRDs}

Between 1999 and 2002, two WRDs at Korbussen and Drosen were relocated to the WRD Beerwalde. A surface cover was placed on the reshaped and newly constructed WRD Beerwalde. Prior to placement of waste rock materials on the extension area, a drainage system and a base sealing layer were constructed. Currently the covered WRD is ca. $43 \mathrm{~m}$ high. The surface consists of a central plateau area on top and surrounding slopes with two to three berms (O'Kane at al., 2011). The major part of the surface of the WRD Beerwalde has a two-layer cover, constructed during the remedial period up to 2002 and consisting of a storage layer greater than $1.5 \mathrm{~m}$ and an underlying sealing layer of at least $0.4 \mathrm{~m}$. The sealing layer material consists of a quaternary clayey loam compacted to a degree of proctor density $\left(D_{\mathrm{Pr}}\right)$ exceeding $95 \%$. This layer is to ensure a saturated hydraulic conductivity $\left(\mathrm{k}_{\mathrm{f}}\right)$ of less than $1 \mathrm{E}-9 \mathrm{~m} / \mathrm{s}$ as built. The storage layer material consists of a mixture of a sand layer and an overlying loam excavated in one cut in a quarry and transported as a mixture to the site. This mixture was spread on the reshaped dump and placed in two or three lifts. The soil physical properties of the storage layer vary locally and depend on the soil mixture placed. On average, the storage layer exhibited a saturated hydraulic conductivity of $3 \mathrm{E}-7 \mathrm{~m} / \mathrm{s}$ and an available field capacity of about $28 \%$ vol after construction.

The lower part of the western dump slope is still covered by a single-layer cover of loam (1.2 m thick) placed during the 1980s. This part remained undisturbed and in place during remediation works in accordance with the valid mining law permits. Here large trees have become established. On the two-layer cover, trees with a height of several meters have been established to date. The area between the trees is grassland. Figure 1 shows the schematic designs of the two-cover designs on the WRD Beerwalde. The percolation criterion to be met by the two-layer cover for a period of the first five years after cover placement was defined to be no more than $5 \%$ of the annual precipitation on the entire surface of the covered WRD. According to the cover design, the annual percolation rate through the final cover should be minimised further by the established forest due to evapotranspiration.

\section{Investigation methodology}

Site instrumentation includes lysimeters for quantifying percolation and lateral flow and soil hydrological probe measurements for monitoring cover water dynamics. The parameters of soil temperature, water content and soil suction are ascertained at each study sites by probes. The registered time series of all 
parameters are analysed with regard to the respective depth and are processed annually for a model calibration purposes.

The basic result of hydrological monitoring is the establishment of the annual water balance, which in turn will serve as the basis for contaminant balances. For WRD Borbachdamm and for WRD 366 at the Schlema site, a model-based water balance was established on an annual basis using local meteorological data. The Swedish model CoupModel (Jansson and Karlberg, 2012) was calibrated on the basis of soil probe data (depth-related soil suction and soil moisture), and the computed water balance was checked against flow measurements. The CoupModel uses physically based algorithms for the calculation of fundamental water balance processes. Only selected measurement results of the WRD Beerwalde were also checked by a water balance modelling. The measured results of Station MS 7 were recalculated for five years (2004-08) with the HELP model (Schmidt, 2010). Hereinafter, the more detailed results of the model-based water balances for the dumps at the Schlema site are summarised and evaluated. The values of 2012 have to be considered as provisional data because the research on modelling is still in progress.

Water balance modelling was based on stepwise input of parameters and initially calibrated with grass reference evapotranspiration data. Variations of vegetation parameters were taken into consideration on an annual basis. Model parameters were adjusted to allow optimum simulation of measured soil suction, water content and soil temperature data before calculation of water balance. An extensively statistical analysis was not carried out. This kind of examination was limited to analysis of the correlation between measured and model values of percolation.

\subsection{Measurement setup at WRD Borbachdamm (Schlema/Saxony)}

In 1999, soil probes were installed at depths of $0.4 \mathrm{~m}$ and $0.8 \mathrm{~m}$ within the cover (mineral soil) to investigate soil water dynamics. Figure 2 depicts the measurement system in place. A total of 24 soil probes had been installed within the cover, 8 of which ceased functioning due to old age during the course of the investigation from 1999 to 2012. To date, 16 probes remain operational. Figure 2 shows the installed types of soil probes and their logged data and illustrates water balance components. In addition to the soil probes, a lysimeter (GL112) with an effective surface area of $10 \mathrm{~m}^{2}$ is operated in their immediate vicinity (distance about $50 \mathrm{~m}$ ) to monitor cover percolation (RU). The lysimeter is buried at a depth of about $1 \mathrm{~m}$ beneath the cover within the waste rock material. In addition to drainage of percolation water, there is a catchment system to collect the lateral flow (RH) in the cover by lysimeteer. Flow rates are determined by regular volumetric metering of a collection vessel.

\subsection{Measurement setup at WRD 366 (Schlema/Saxony)}

The soil probes were installed during November 2004 in the same depths of $0.4 \mathrm{~m}$ and $0.8 \mathrm{~m}$ as on the WRD Borbachdamm. Figure 2 illustrates the currently operated measuring system involving 20 active soil probes. Table 2 gives information on the installed probes and their characteristics. In 2004, a slope lysimeter station was set up in the immediate vicinity of the soil probes. The station integrates two lysimeters (HDPElysimeters with an inner diameter of $1 \mathrm{~m}$, about $1.2 \mathrm{~m}$ deep) on the upper slope and another two on the lower slope (open upwards to the slope), which permit quantification of lateral flow (RH) within the cover as well as the cover percolation rate (RU). In addition, a large lysimeter with an effective surface area of $10 \mathrm{~m}^{2}$ installed on WRD 366 at a distance of about $200 \mathrm{~m}$ from the soil measuring site has operated since 2002 , which also ascertains cover percolation. 


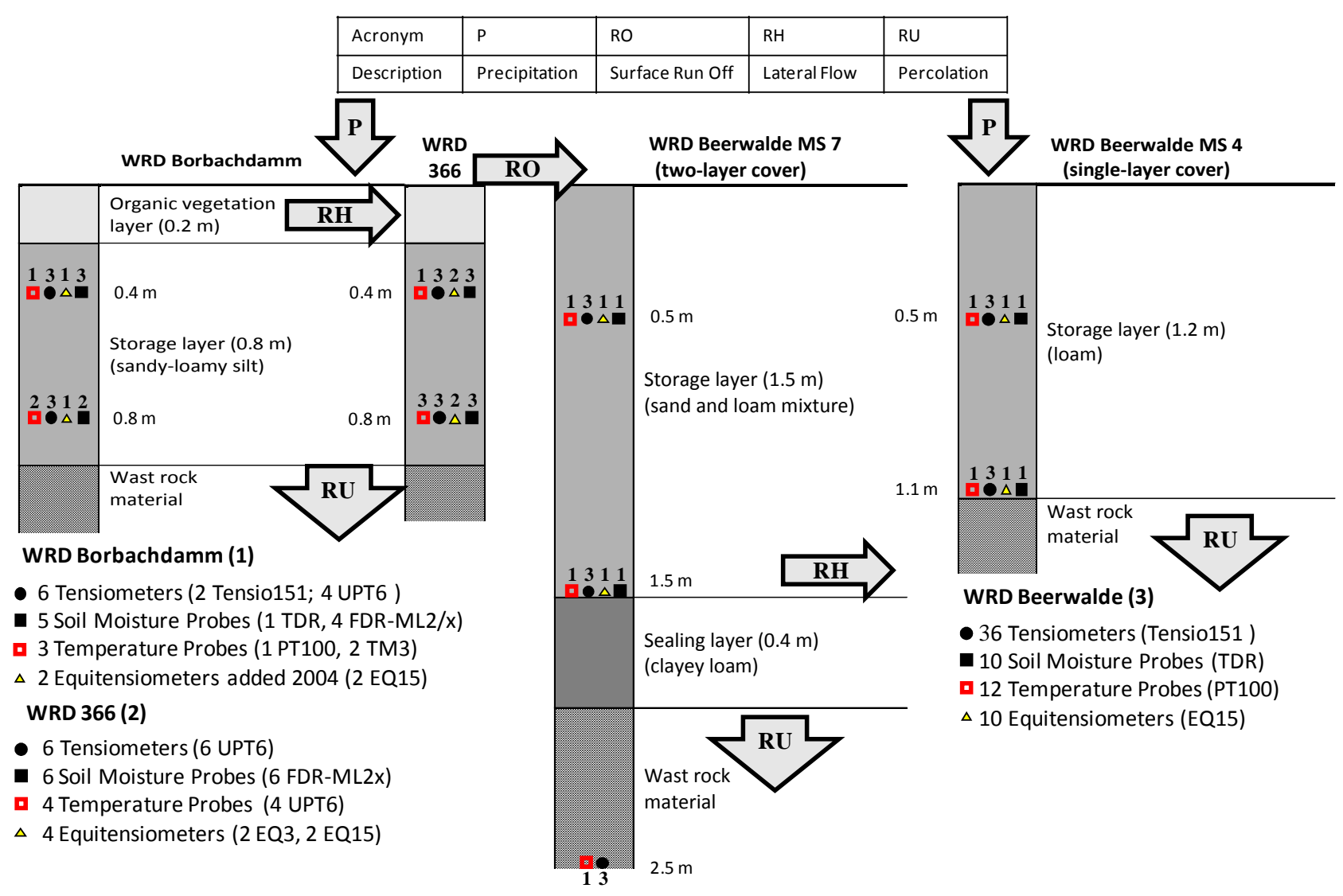

Figure 2 Cover systems and measurement setups of WRDs

Table 2 Characteristics of soil probes

\begin{tabular}{cccc}
\hline Parameter & Probe & Types & Measurement Range \\
\hline Water content & Soil moisture sensor & FDR-ML2(x)/TDR & 0 to $100 \% \mathrm{Vol}$ \\
Soil temperature & Temperature sensor & PT100/UPT6 & -100 to $200 / 0$ to $60^{\circ} \mathrm{C}$ \\
Soil suction & Tensiometer & Tensio151/UPT6 & 0 to $850 \mathrm{hPa}$ \\
& Equitensiometer & EQ3/EQ15 & 250 to 3,000/500 to $15,000 \mathrm{hPa}$ \\
\hline
\end{tabular}

\subsection{Measurement setup at WRD Beerwalde (Ronneburg/Thuringia)}

A comprehensive hydrological monitoring system was installed in order to measure the daily water balance of the final cover. In total, seven hydrological monitoring stations were installed on the cover. The stations are distributed on the WRD with regard to different expositions of the dump slopes. Six hydrological monitoring stations were built in the two-layer cover. The hydrological monitoring stations MS 2 und MS 7 in the two-layer cover are examples of northern and southwestern expostion. One station (MS 4) was located in the single-layer cover. The locations of all monitoring stations are shown in Figure 3 . The results of selected monitoring stations (MS 2/4/7) provide a maximum range of measurement data for the water balance. This range also includes the results of the other monitoring stations at the WRD Beerwalde. 


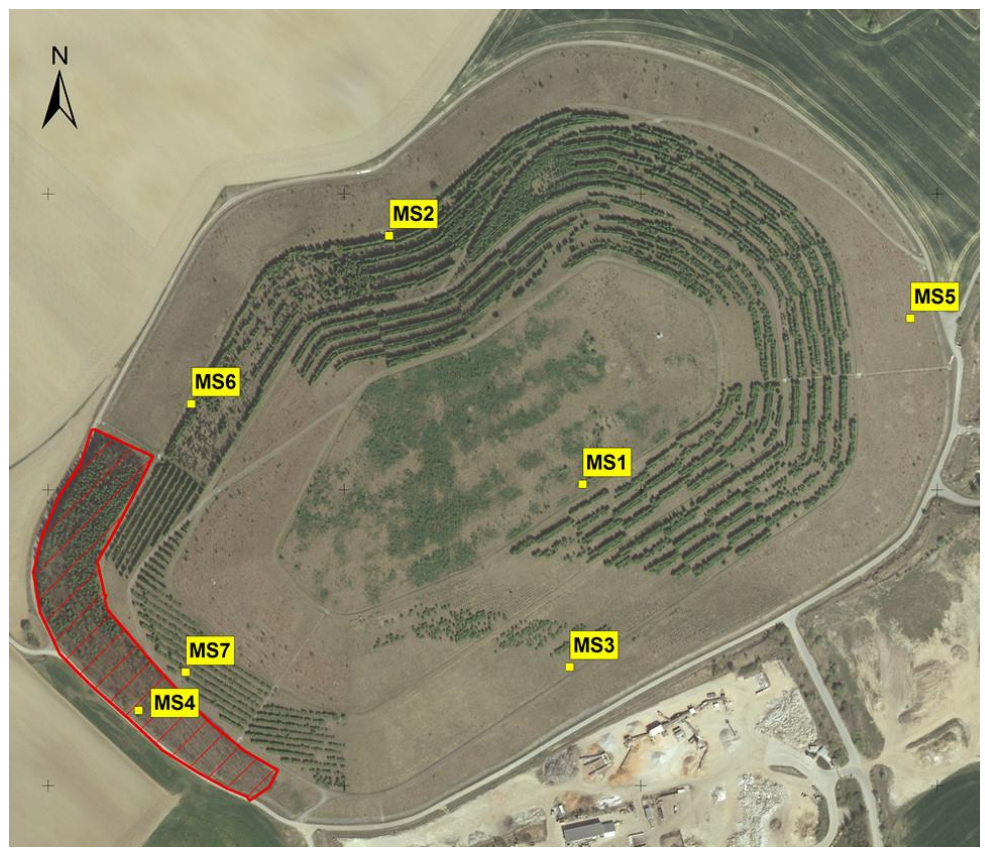

Figure 3 Aerial photo of the WRD Beerwalde showing locations of the hydrological monitoring stations (MS1-MS7) and sector of single-layer cover (shown in red)

The monitoring stations were equipped with lysimeters for measuring the surface runoff (RO), lateral flow within the storage layer and percolation through the sealing layer. In addition, more than 50 probes were installed at different depths $(0.5 \mathrm{~m}, 1.1 \mathrm{~m}$ and $1.5 \mathrm{~m})$ to measure water content and soil suction (Figure 2). Some monitoring stations were also equipped with an automatic rain gauge with tipping counter. The monitoring station on the central plateau area (MS 1) includes an automatic weather station with sensors for monitoring air temperature, air pressure, air humidity and precipitation.

\section{Results of measurements and discussion}

As the development of this parameter over time illustrates, graphic representation of probe measurement time series is restricted to soil moisture (diagrams) and measured annual flows (tables). In addition to these data, the paper also gives some interesting information on soil suction data and soil temperatures (but without detailed presentation). Also, the data of the surface runoff and lateral flow at the WRD Beerwalde are presented as a summary of all monitoring stations.

\subsection{WRD Borbachdamm}

Since November 1999 the soil probes have provided a continuous time series with only a few data gaps. Figure 4 depicts the time series of soil moisture at 0.4 and $0.8 \mathrm{~m}$ depth for the monitoring period. About three years after cover construction, soil moisture began to exhibit a distinct annual cycle. From 2004, in addition to the seasonal factor, the influence of willow growth and root water uptake manifested itself in enhanced soil moisture dynamics. At the beginning, the influence of root water uptake by willow plants was discernible mainly in the upper 0.4-m horizon, but it was also evident in the 0.8-m depth from 2006. This is an indication of root growth into deeper soil layers and of enhanced root water uptake. Furthermore, seasonal soil water losses in cover material increased with time since cover construction. Also, plant water use increases as vegetation matures. The difference between minimum and maximum soil moisture levels during the growing season is indicative of that loss. For the 0.4-m measurement level, that difference has risen from an initial $4 \%$ vol under grass cover to $30 \%$ vol under the influence of willow growth. Time series data are also affected by the respective meteorological boundary conditions. For example, during the summer months, when isolated pulse rainfall events occurred, this resulted in rapid increase in soil moisture, in particular at the 0.4-m depth (e.g., 2006/2009/2011). 


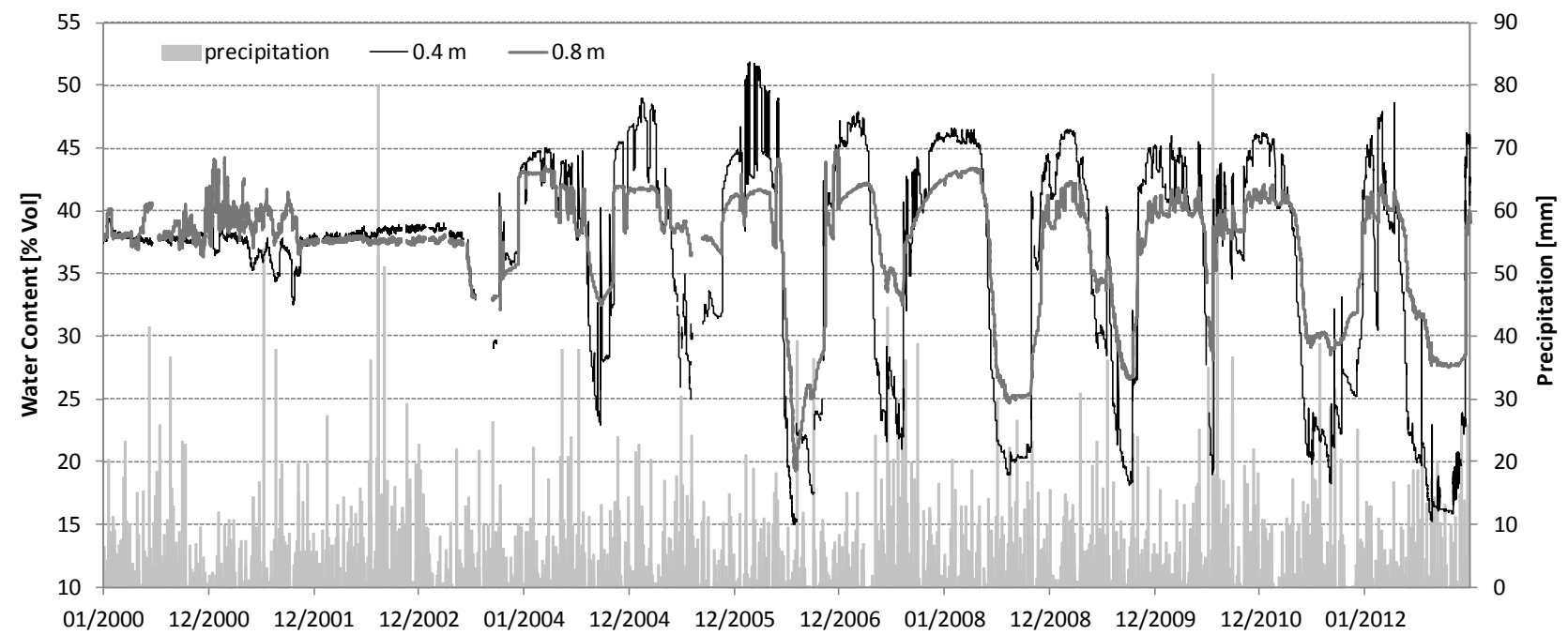

Figure 4 Development of water content in the cover, WRD Borbachdamm

Simultaneously acquired soil suction data provide an indication of pondage in mineral soil in winter month. The development of maximum values in summer was influenced by advanced growth of vegetation. Starting in 2006 (the seventh vegetation period), clearly elevated soil suction amounting up to $15,000 \mathrm{hPa}$ (pF 4.2 wilting point range) occurred under the influence of willow stands in the top 0.4-m depth during the summer months. In the meantime, increased soil suction that is typical of tree populations was also observed at the lower monitoring horizon. At a depth of $0.8 \mathrm{~m}$, increasing soil suction was still discernible up to the 2012 growing season, while no further increase was on record at the $0.4 \mathrm{~m}$ level, possibly indicating the development of a deep root system.

The development of plant growth can also be deduced from the decline in soil temperatures caused by canopy shading. As a consequence and as time went by, clearly decreased soil temperatures were registered during the summer months. Since 1999, willow stands on the WRD Borbachdamm have reduced maximum summer temperatures by $5 \mathrm{~K}$ at $0.4 \mathrm{~m}$ depth and by $4 \mathrm{~K}$ at $0.8 \mathrm{~m}$ depth.

Table 3 summarises the annual quantities of percolation and lateral flow measured by lysimeter GL112. As the measuring system does not allow separation of surface runoff from lateral flow in the cover, the measured values have to be considered as the summation of these two flows $(\mathrm{RO}+\mathrm{RH})$. As a rule, flow rates exhibit a clear dependence on precipitation (P). As expected, the sum of surface runoff and lateral flow $(\mathrm{RO}+\mathrm{RH})$ is clearly smaller than percolation and decreases from the fifth year after cover installation (Table 3). The percolation rate generally exceeds $200 \mathrm{~mm} / \mathrm{a}$ except after the dry year in 2004. High percolation rates were recorded each year during the winter months and after snowmelt. In summer months, all flows are very low. The discharge hydrograph (RU) corresponds with the soil probe measurements. Higher flows $(\mathrm{RU} / \mathrm{RO}+\mathrm{RH})$ are observed always under saturated soil conditions. As compared with the years of average precipitation (2001, 2005, 2008 and 2011), there is an approximately steady percolation rate since 2005 on the order of $230-280 \mathrm{~mm} / \mathrm{a}$. In 2001, two years after cover placement and initial seeding, the percolation rate was still much higher, at $416 \mathrm{~mm} / \mathrm{a}$. 
Table 3 Results of lysimeter measurements at WRD Borbachdamm

\begin{tabular}{cccccccccccccc}
\hline Year & 2001 & 2002 & 2003 & 2004 & 2005 & 2006 & 2007 & 2008 & 2009 & $\mathbf{2 0 1 0}$ & $\mathbf{2 0 1 1}$ & $\mathbf{2 0 1 2}$ & $\varnothing$ \\
\hline $\mathrm{P}(\mathrm{mm})$ & 853 & 1,199 & 575 & 910 & 892 & 767 & 1,054 & 850 & 943 & 1,314 & 826 & 993 & 931 \\
$\mathrm{RU}$ & 416 & 959 & 261 & 166 & 234 & 231 & 530 & 272 & 497 & 576 & 279 & 282 & 392 \\
$\begin{array}{c}\mathrm{mm}) \\
\mathrm{RO}+\mathrm{RH} \\
(\mathrm{mm})\end{array}$ & 272 & 398 & 87 & 112 & 66 & 35 & 22 & 25 & 29 & 41 & 24 & 11 & 93 \\
\hline
\end{tabular}

\section{$3.2 \quad$ WRD 366}

Beginning in 2007 the measurement site was subdivided into the grassland sector and the grey alder sector. According to their location, soil probes were assigned to their respective type of vegetation. During the preceding period of 2004-06, measured data were averaged according to depth and assigned to grass vegetation. Figure 5 depicts a time series of soil moisture for the entire investigation period.

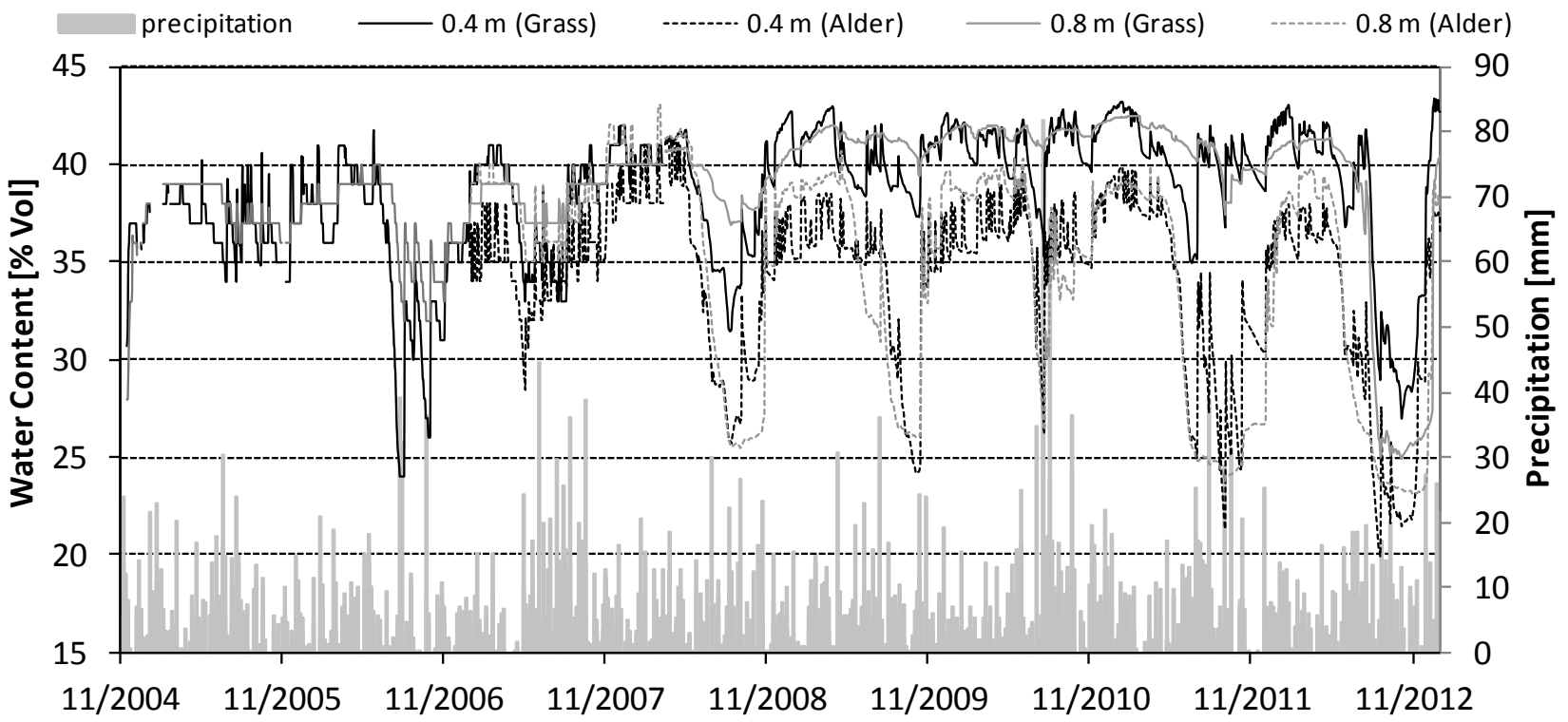

Figure 5 Development of water content in the cover, WRD 366

Barely two years after cover installation, a pronounced annual cycle of soil moisture became apparent in 2006, which indicated that stable grass vegetation had established itself. From the 2008 growing season on the influence of grey alder saplings becomes clearly recognisable by higher soil moisture depletion. In 2007 that influence was still restricted to the upper 0.4-m horizon. The time series suggests that in 2008 a deep alder root penetration and, as a consequence, root soil moisture uptake shifted downwards. This was the only year with average precipitaton when elevated water loss was observed in the grassed cover caused by a dry vegetation period. Furthermore, an increasing difference between maximum and minimum soil moisture levels during the vegetation period was observed as time went by. For the 0.4-m measurement level, that difference has risen from an initial $4 \%$ vol under grass cover to $17 \%$ vol. Under grey alder stands, the difference at the $0.4-\mathrm{m}$ level amounts up to $19 \%$ vol. After cover completion, the difference under grass cover at the deeper measurement horizon also amounted to $4 \%$ vol, while in 2011 the readings were $18 \%$ vol under grass cover and $23 \%$ vol under the influence of alders. Distinction between types of vegetation within the comparatively small measurement area is justified for the period from 2007 to mid-2012 only. With their advancing growth during the 2012 vegetation period, the grey alder influence has extended into the range of the soil probes under grass vegetation. 
In contrast to soil suction measurements performed at WRD Borbachdamm, data from WRD 366 do not suggest regular ponding in the cover in wet periods. Beginning in 2009 (fifth vegetation period), clearly elevated soil suction amounting up to $11,000 \mathrm{hPa}$ occurs at both measurement horizons during the summer months. This suggested enhanced root water uptake by the dominant tree population. At a depth of $0.8 \mathrm{~m}$, increasing soil suction was still discernible up to the 2012 vegetation period, while no further increase was recorded at the $0.4 \mathrm{~m}$ level. This is an indication that further root growth is primarily oriented downwards or that a deep root system developed.

The soil temperature time series for WRD 366 provided a similar picture as at the WRD Borbachdamm. Lower soil temperatures during the summer months were observed as early as three years after cover placement. A further temperature drop was observed five years after cover placement. The development of grey alder stands on WRD 366 has reduced maximum summer soil temperatures at $0.4 \mathrm{~m}$ depth by $5 \mathrm{~K}$ and at $0.8 \mathrm{~m}$ by $4 \mathrm{~K}$ through canopy shading.

Table 4 summarises the annual quantities of precipitation, percolation rate and lateral flow measured by several lysimeters (GL115 and $\mathrm{OH}$ ).

Table 4 Results of lysimeter measurements at WRD 366

\begin{tabular}{ccccccccccccc}
\hline Year & 2002 & $\mathbf{2 0 0 3}$ & $\mathbf{2 0 0 4}$ & $\mathbf{2 0 0 5}$ & $\mathbf{2 0 0 6}$ & $\mathbf{2 0 0 7}$ & $\mathbf{2 0 0 8}$ & $\mathbf{2 0 0 9}$ & $\mathbf{2 0 1 0}$ & $\mathbf{2 0 1 1}$ & $\mathbf{2 0 1 2}$ & $\varnothing$ \\
\hline $\mathrm{P}(\mathrm{mm})$ & 1,199 & 575 & 910 & 933 & 744 & 1,011 & 789 & 999 & 1,451 & 826 & 993 & 948 \\
$\mathrm{RU} \mathrm{GL115}$ & 625 & 113 & 267 & 277 & 171 & 221 & 166 & 180 & 441 & 136 & 138 & 249 \\
$(\mathrm{~mm})$ & & & & & & & & & & & & \\
$\mathrm{RU} \mathrm{OH}(\mathrm{mm})$ & & & & 114 & 128 & 385 & 280 & 335 & 471 & 179 & 238 & 266 \\
$\mathrm{RH} \mathrm{OH}(\mathrm{mm})$ & & & & 5 & 6 & 40 & 20 & 20 & 23 & 7 & 19 & 17 \\
\hline
\end{tabular}

Also at this dump, flow volumes are a function of precipitation. As one would expect, the lateral flow rate in the cover is clearly less than percolation and accounts for a maximum of $4 \%$ of precipitation. In contrast to WRD Borbachdamm, this flow can separated from surface runoff by the special construction of the surface lysimeters. Due to the southern exposition of slope, percolation measured by these lysimeters is less than that at the northern-exposed WRD Borbachdamm and, excluding wet years, amounts for the most part to less than $200 \mathrm{~mm} / \mathrm{a}$. Compared with years with mean precipitation (2005, 2008 and 2011), percolation exhibits a decreasing trend that is attributable to the increasing influence of vegetation on cover hydrology. As a general rule, elevated flows ( $\mathrm{RU}$ and $\mathrm{RH}$ ) are observed during the winter months due to snowmelt. As a consequence, flow measurements correspond with soil probe data and altogether exhibit plausible results.

\subsection{WRD Beerwalde}

This section discusses some relevant results of the hydrological field measurements of the MS 2, MS 7 und MS 4 for 2002-12 at the WRD Beerwalde. Figure 6 shows the temporal patterns of soil moisture in the cover material of the two-layer cover for the two hydrological monitoring stations (MS 2 and MS 7).

One year after cover completion the water content began to exhibit a distinct annual cycle in response to seasonal meteorological changes. At the beginning, this influence is distinct mainly in the upper 0.5-m horizon and in the lower 1.5-m depth from 2006 onwards. The sharp decline between 2003 and 2004 is an effect of the minor rainfall in 2003. Starting from 2006 the vegetation growth on the cover surface led to more intense dewatering in the cover material during the summer months, particularly at the monitoring station with a southwestern exposition (MS 7). This indicates the deep root growth enhancing drawdown of soil water content. 


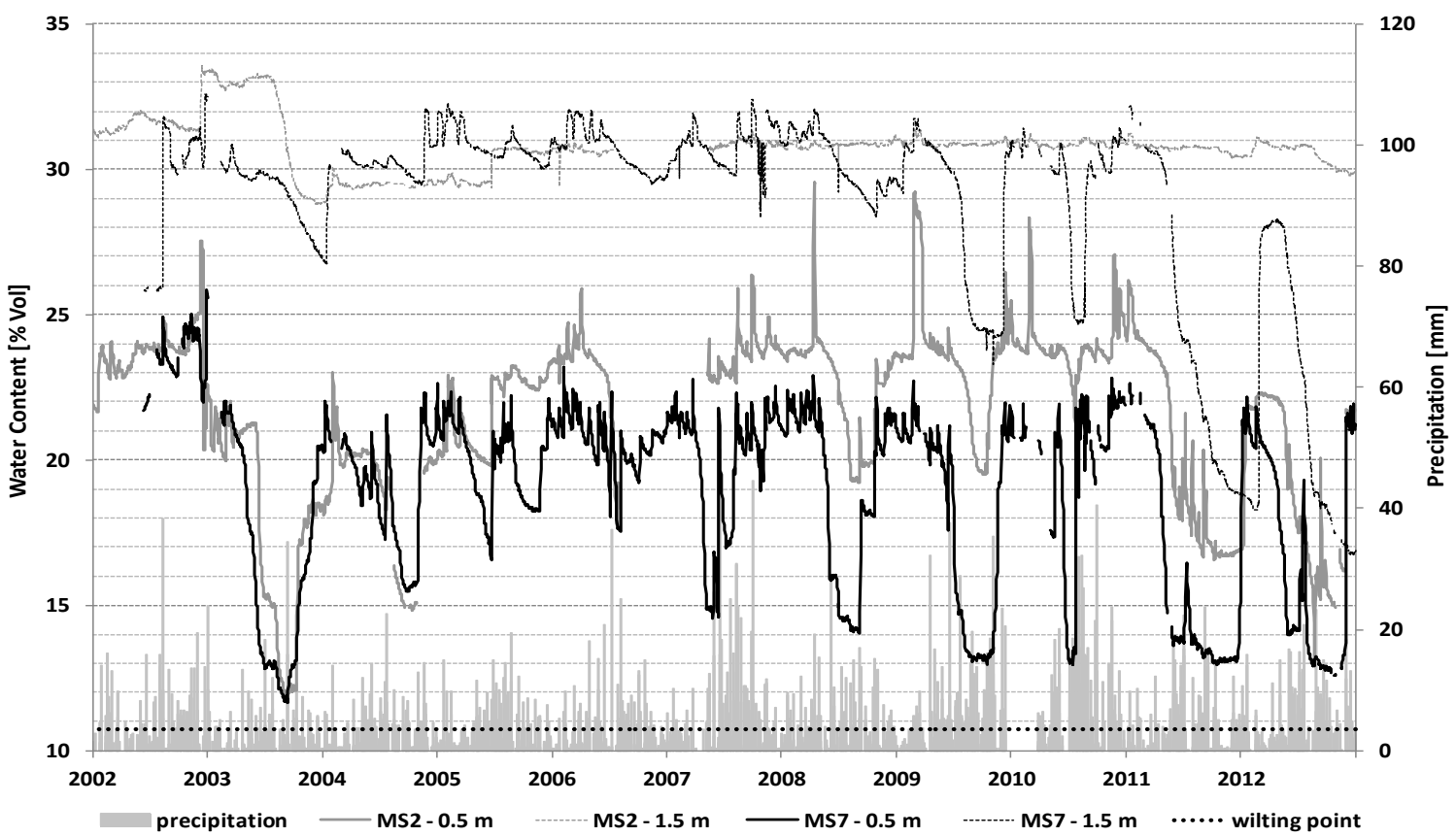

Figure 6 Development of the water content at the stations MS 2 and MS 7

During the monitoring period the evapotranspiration rate at station MS 7 is higher than at MS 2. Especially near the surface $(0.5 \mathrm{~m})$, the water content at the MS 7 decreases significantly close to wilting point in summer months starting from 2007 (Figure 6). In the lower $1.5 \mathrm{~m}$ at the MS 7, the significant decrease in water content began in 2009. During the last two years of the monitoring period the water content in the lower $1.5-\mathrm{m}$ depth at MS 7 decreased to a minimum value comparable to the upper $0.5-\mathrm{m}$ horizon.

By contrast, the water content in the lower part of the storage layer $(1.5 \mathrm{~m})$ at MS 2 is relatively constant in the range of the field capacity during the entire reported period. Due to the northern exposition at MS 2, solar radiation is lower than at MS 7 (southern exposition). Thus evapotranspiration at MS 2 is less than that at MS 7.

Figure 7 shows the temporal patterns of soil water content influenced by the same exposition in different cover systems at different states of vegetation development. The water content at MS 4 (single-layer cover with established forest vegetation) exhibits large variations over the whole thickness of the storage layer. At MS 7 (two-layer cover), the variation in water content increases with the ongoing maturation of vegetation cover (trees). Here the water content shows significant variations over the whole thickness of the storage layer for the first time in 2009 (O'Kane et al., 2011).

The soil suction data also show the effect of maturation of the vegetation on the cover surface. The soil suction at a certain depth increased, depending on exposition of the cover surface over the reported period. Especially on slopes with southern exposition, the soil suction increased near to wilting point. The development of plant growth during the monitoring period can also be indicated from the development of soil temperatures. Compared with the monitoring station at the Schlema site, a significant decreasing of the soil temperatures was registered during the summer months.

Due to the different water contents in the cover system, its exposition and the state of the establishment of vegetation, the annual percolation rate varies typically at the three hydrological monitoring stations (Table 5). At station MS 4, with a $1.2 \mathrm{~m}$ single-storage layer and mature forest vegetation, the percolation decreased from $230 \mathrm{~mm}$ in 2002 to $3 \mathrm{~mm}$ in 2012 (percolation rate of $0.4-28.6 \%$ of annual precipitation) due to fluctuations in annual precipitation. The annual percolation rate at the stations in the two-layer cover system is usually lower than at MS 4. But there are also differences between the measured percolation rates at the MS 2 and MS 7. At station MS 2, exposed to the north, the annual percolation rate did not rise above $1.4 \%$ of the annual precipitation rate $(9 \mathrm{~mm}$ in 2010) during the entire period from 2002 
to 2010. Since 2011 the percolation rate has increased to a maximum value of $43 \mathrm{~mm}$ per year (percolation rate of $6.9 \%$ of annual precipitation). In contrast, the annual percolation rate of MS 7 increased with time until 2010. The maximum percolation rate of $173 \mathrm{~mm}$ was measured at the MS 7 in 2010. In 2011 and 2012, the percolation at MS 7 decreased to a minimum of $3 \mathrm{~mm}$ (Table 5). The reasons are the low and uniformly distributed precipitation combined with the high evapotranspiration of the developed forest vegetation. The percolation rates measured at MS 1/3/6 are comparable to the results of MS 2 and MS 7 and were influenced by exposition. The average percolation rate of all monitoring stations for the cover system at the WRD Beerwalde amounts to $8 \%$ of precipitation for the monitoring period. Therefore, the two-layer cover failed to meet design criterion of less than $5 \%$ of incident rainfall.

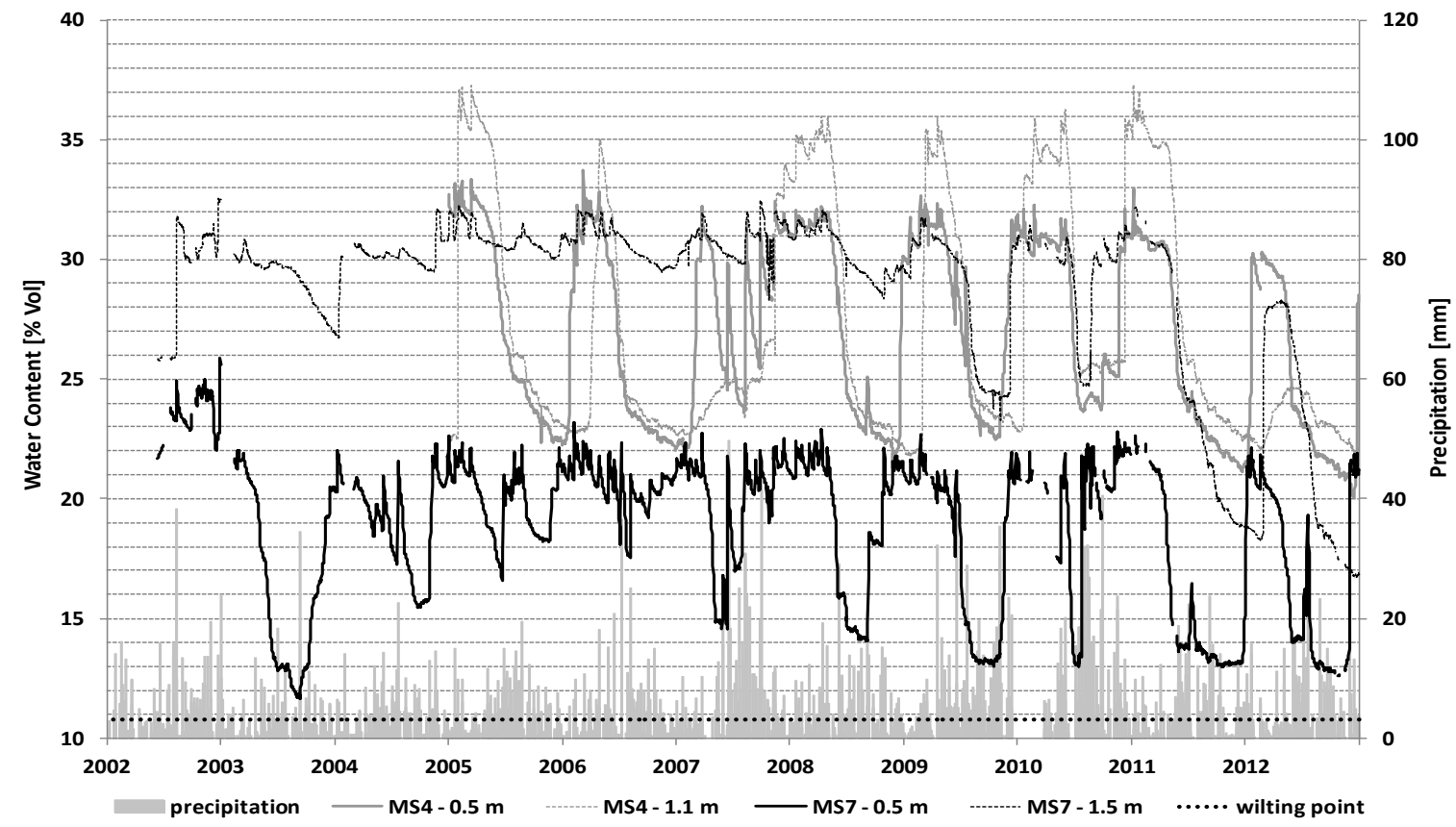

Figure 7 Development of the water content at the MS 4 and MS 7

Table 5 presents the annual percolation rates of selected lysimeters at the WRD Beerwalde.

Table 5 Percolation (RU) of selected lysimeters at the WRD Beerwalde

\begin{tabular}{ccccccccccccc}
\hline Year & $\mathbf{2 0 0 2}$ & $\mathbf{2 0 0 3}$ & $\mathbf{2 0 0 4}$ & $\mathbf{2 0 0 5}$ & $\mathbf{2 0 0 6}$ & $\mathbf{2 0 0 7}$ & $\mathbf{2 0 0 8}$ & $\mathbf{2 0 0 9}$ & $\mathbf{2 0 1 0}$ & $\mathbf{2 0 1 1}$ & $\mathbf{2 0 1 2}$ & $\varnothing$ \\
\hline $\mathrm{P}(\mathrm{mm})$ & 804 & 450 & 550 & 540 & 543 & 860 & 624 & 875 & 950 & 544 & 628 & 670 \\
RU MS 2 (mm) & 4 & 4 & 2 & 1 & 6 & 0 & 8 & 8 & 9 & 19 & 43 & 10 \\
RU MS 7 (mm) & & 10 & 8 & 25 & 24 & 73 & 31 & 119 & 173 & 43 & 3 & 51 \\
RU MS 4 (mm) & 230 & 107 & 48 & 78 & 77 & 63 & 100 & 85 & 204 & 98 & 3 & 86 \\
\hline
\end{tabular}

The surface runoff and the lateral flow decreased continuously during the monitoring period. The measurements directly after cover construction works (2002/2003) showed an RO and an RH of about $20 \%$ of precipitation for each flow type. Only $6-9 \% \mathrm{RO}$ and $2 \% \mathrm{RH}$ were measured at the end of the study period. 


\section{$4 \quad$ Water balance modelling results}

\subsection{WRD Borbachdamm}

Results of annual balances for WRD Borbachdamm are shown in Table 6 (Löser et al., 2012). Model calibration based on soil probe data was in every case successfully accomplished (visual comparison of time series). Subsequent matching of data with lysimeter investigations revealed that good consistency of flows is only achievable when total flow $R(R O+R H+R U$ ) is being compared (monthly values $r=0,6)$. In flow measurements by means of lysimeters some interfering factors may appear that might result in higher water volumes and put the separation of several flows into question (influence of surface runoff, ingress via preferred flow channels from a larger than assumed catchment area). Such interfering factors are of particular relevance during wet periods and are likely to have distorted percolation rates recorded for 2002, 2007 and 2009. The measured total flow R of $485 \mathrm{~mm}$ as the average value for 2001-12 stands in contrast to a model-based total flow of $371 \mathrm{~mm}$. In addition to the mentioned interfering factors, a certain balance discrepancy between measurement and modelling would make sense as there are no willows growing in the lysimeters' sphere of influence and hence real evapotranspiration of the lysimeter catchment area is smaller. As a consequence, percolation in the lysimeter catchment area is greater than that computed by the model.

Table 6 Model-based water balance, WRD Borbachdamm measuring site

\begin{tabular}{cccccccccccccccccc}
\hline Year & 1999 & 2000 & 2001 & 2002 & 2003 & 2004 & 2005 & 2006 & 2007 & 2008 & 2009 & 2010 & 2011 & 2012 & $\varnothing$ \\
\hline $\begin{array}{c}P \\
(\mathrm{~mm})\end{array}$ & 878 & 877 & 853 & 1,199 & 575 & 910 & 892 & 767 & 1,054 & 850 & 943 & 1314 & 826 & 1,028 & 926 \\
$\begin{array}{c}\mathrm{ETR} \\
(\mathrm{mm})\end{array}$ & 300 & 358 & 462 & 312 & 423 & 445 & 566 & 571 & 714 & 618 & 693 & 552 & 629 & 689 & 524 \\
$\begin{array}{c}\mathrm{RO} \\
(\mathrm{mm})\end{array}$ & 67 & 164 & 16 & 344 & 43 & 61 & 101 & 100 & 118 & 139 & 82 & 77 & 86 & 74 & 103 \\
$\begin{array}{c}\mathrm{RU} \\
(\mathrm{mm})\end{array}$ & 503 & 438 & 300 & 544 & 181 & 332 & 238 & 171 & 151 & 166 & 121 & 583 & 227 & 203 & 297 \\
$\begin{array}{c}\Delta \mathrm{S} \\
(\mathrm{mm})\end{array}$ & 8 & -54 & 75 & -1 & -72 & 72 & -12 & -61 & 72 & -73 & 47 & 103 & -116 & 62 & 2 \\
\hline
\end{tabular}

Regional grass reference evapotranspiration, which is identified as a short grass crop, is on the order of about $550 \mathrm{~mm} / \mathrm{a}$. It takes about five to six years following completion of cover placement and initial vegetation to reach such evaporation performance at the study site. With the increasing influence and the advanced development of willow stands, real evapotranspiration amounts up to $135 \%$ of grass reference evapotranspiration. Consequently, vegetation verifiably performs its function of reducing percolation rates. According to the 14-year water balance and without regard to the 2002 and 2010 wet years, percolation rates have fallen from $31-57 \%$ of precipitation during the initial five years of water balance modelling to $13-27 \%$ during the recent five years of modelling. As a consequence of the aforementioned interfering factors, lysimeter measurements performed during the recent five years of measurement exhibit indeed higher percentages but basically an identical temporal trend.

\subsection{WRD 366}

Beginning in 2007, two separate models were employed that differed from each other in terms of vegetation parameters (grass and grey alder, due to subdivision in two vegetation sectors). Annual results are documented in Tables 7 and 8 (Löser et al., 2012). 
Model calibration based on soil probe data (soil moisture and suction) was conducted separately for each type of vegetation. In doing so, time series of the model exhibited good consistency with measurements (visual comparison). When comparing modelling results to lysimeter volumetric measurements, it became apparent that the model generally computes higher percolation rates (Tables 4 and 7). The greatest discrepancies exist with regard to the volumes measured by lysimeter GL115. These are most probably due to the exposed location of the lysimeter and the earlier placement of the cover in the lysimeter area, possibly due to minor disparities in the soil composition of the cover. The lysimeters on the upper slope $(\mathrm{OH})$ were installed in the immediate vicinity of the soil probe monitoring site. Cover material in these lysimeter types $(\mathrm{OH})$ is identical with that of the soil probe monitoring site. For 2007-12, modelled percolation rates show good agreement with volumes recorded by lysimeters on the upper slope (monthly values $r=0.7)$. The measured percolation rate for $2007-12$ of $315 \mathrm{~mm}$ stands in contrast to the modelled percolation rate of $334 \mathrm{~mm}$ (Tables 4 and 8, grey alder).

Grass reference evapotranspiration was already achieved in the third year following cover placement completion and initial vegetation establishment. With the increasing influence of the mature alder, evapotranspiration rose to $128 \%$ of grass reference evapotranspiration. With abundant and mature alder, real evapotranspiration under grass would be up to $200 \mathrm{~mm}$ lower than that under grey alder. For some time, grass was mowed regularly on part of the test area. Estimation of actual evapotranspiration for the mown part of the test area revealed a reduced evaporation of about $100 \mathrm{~mm}$ compared with the nonregularly mown grass area. Modelling allows comparison of evapotranspiration and percolation rates under grass and tree vegetation. According to the eight-year water balance, and without regard to the 2010 wet year, percolation has fallen from $28-67 \%$ of precipitation during the initial five years of water balance modelling under grass to $24-38 \%$ during the recent five years of water balance modelling under trees. Despite the aforementioned varying topographical conditions, lysimeter measurements (GL/OH) conducted during the recent five years of measurement yielded similar percolation rates, though with a larger range of 14-35\%.

Table 7 Model-based water balance measuring site WRD 366 , Grass vegetation

\begin{tabular}{cccccccccc}
\hline Year & $\mathbf{2 0 0 5}$ & $\mathbf{2 0 0 6}$ & $\mathbf{2 0 0 7}$ & $\mathbf{2 0 0 8}$ & $\mathbf{2 0 0 9}$ & $\mathbf{2 0 1 0}$ & $\mathbf{2 0 1 1}$ & $\mathbf{2 0 1 2}$ & $\varnothing$ \\
\hline P $(\mathrm{mm})$ & 933 & 744 & 1,011 & 789 & 999 & 1,451 & 826 & 878 & 954 \\
ETR $(\mathrm{mm})$ & 469 & 440 & 551 & 434 & 461 & 477 & 671 & 641 & 518 \\
RO $(\mathrm{mm})$ & 24 & 144 & 4 & 1 & 27 & 237 & 55 & 22 & 64 \\
$\mathrm{RU}(\mathrm{mm})$ & 415 & 210 & 446 & 353 & 500 & 670 & 210 & 228 & 379 \\
$\Delta \mathrm{S}(\mathrm{mm})$ & 27 & -50 & 10 & 1 & 11 & 67 & -110 & -13 & -7 \\
\hline
\end{tabular}

Table 8 Model-based water balance measuring Ssite WRD 366, Grey alders vegetation

\begin{tabular}{cccccccc}
\hline Year & $\mathbf{2 0 0 7}$ & $\mathbf{2 0 0 8}$ & $\mathbf{2 0 0 9}$ & $\mathbf{2 0 1 0}$ & $\mathbf{2 0 1 1}$ & $\mathbf{2 0 1 2}$ & $\varnothing$ \\
\hline $\mathrm{P}(\mathrm{mm})$ & 1,011 & $\mathbf{7 8 9}$ & 999 & 1,451 & 826 & 878 & 992 \\
ETR $(\mathrm{mm})$ & 593 & 505 & 657 & 601 & 676 & 675 & 618 \\
RO $(\mathrm{mm})$ & 14 & 3 & 21 & 195 & 52 & 20 & 51 \\
RU $(\mathrm{mm})$ & 388 & 300 & 307 & 589 & 201 & 218 & 334 \\
$\Delta \mathrm{S}(\mathrm{mm})$ & 16 & -19 & 15 & 66 & -106 & -35 & -11 \\
\hline
\end{tabular}




\section{Summary}

Soil hydrological measurements for the Schlema site demonstrated the effectiveness of cover designs, including vegetation type, with respect to water balance. With increasing vegetation development and change from sparsely growing grass in the early stages to mature tree stands, actual evapotranspiration increased and hence reduced percolation through the cover. Figure 8 demonstrate the changes of water balance after establishment of tree vegetation. These changes are evidenced both by lysimeter data as well as by water balance modelling. Differences in evapotranspiration between grass and tree vegetation are exemplified by data for WRD 366. The results underscore the importance of vegetation for the water balance of WRD covers. In this respect, interception and in particular transpiration is of major importance. As vegetation development advances, the annual model-based water balances provide evidence for the expected change of water balance components in favour of actual evapotranspiration.

Demonstrated by the case study of WRD Beerwalde, slope exposition strongly influences the water balance and consequently the percolation rate through the sealing layer. Consequently, the increasing evaporation led to decreasing water contents and larger soil suction in lower and deeper horizons of the cover. The results show again the major influence of exposition on vegetation development and root depth under the given climate conditions. The annual percolation rate through cover will be more and more controlled by the established trees due to their evapotranspiration. The importance of surface runoff and the lateral flow is decreasing continuously with time.
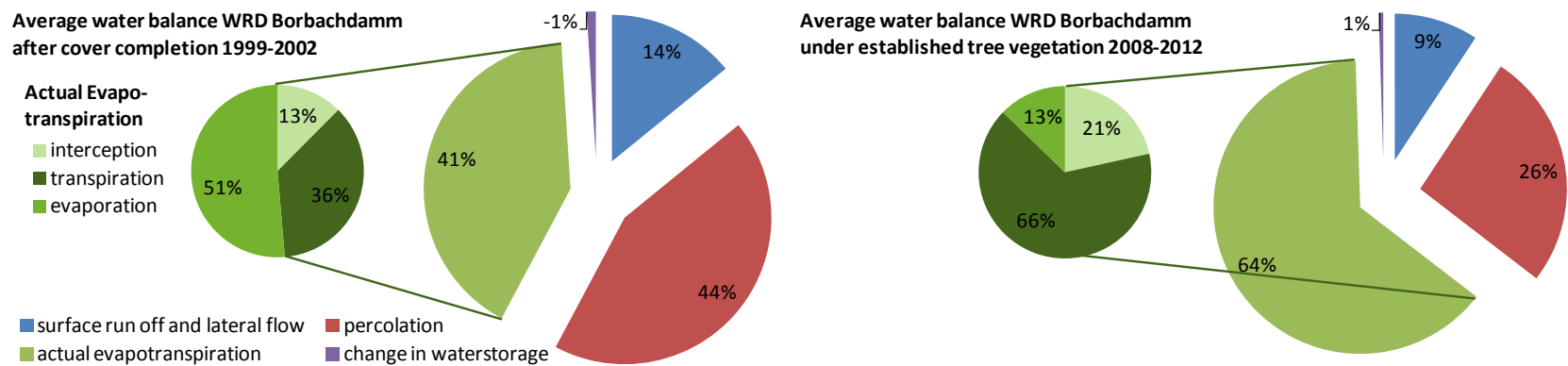

Average water balance WRD 366 after cover completion 2004-2006
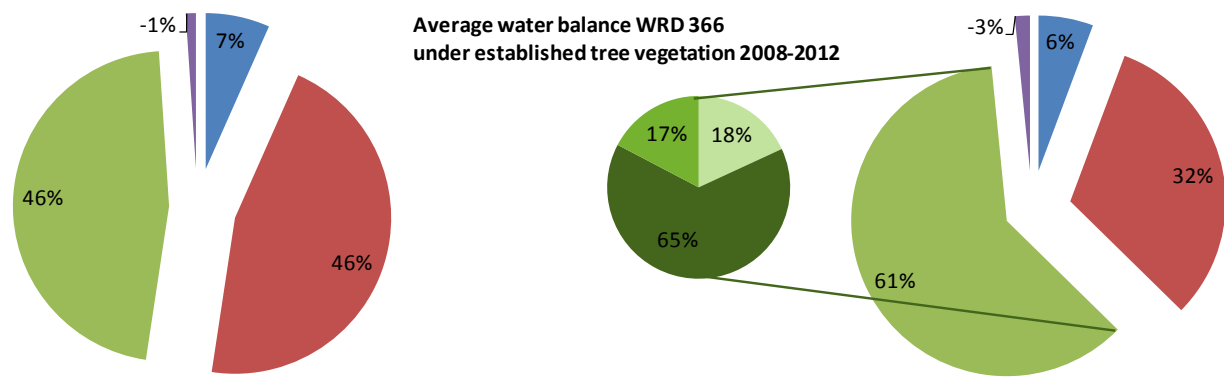

\section{Figure 8 Changes of water balances for WRDs at the Schlema site}

The hydrological researches at the Schlema and Ronneburg site showed the effect of the maturation of the vegetation to cover performance. Compared with the WRD Beerwalde, higher percolation rates were monitored at the Schlema site due to higher annual precipitation rates and the only $1 \mathrm{~m}$ thick two-layer cover without a sealing layer. The two-layer soil cover in combination with plant cover was able to reduce the percolation rate throughout the WRDs at the Schlema site to about one-third of precipitation. In contrast to this, the thicker cover at the Ronneburg site, which includes a sealing layer, was able to reduce the percolation rate through the WRD to about one-tenth of precipitation. So cover systems and material should be chosen according to remediation objectives, such as allowed percolation rate. A low percolation rate can be controlled by a sealing layer with a low hydraulic conductivity. Models including local weather conditions and cover material can help to find the optimal cover system. 


\section{Acknowledgement}

The authors wish to thank Ralf Löser (formerly C\&E GmbH, Technical Adviser (Modelling) and Project Supervisor Dr. Petra Schneider (C\&E GmbH) for their long-standing fruitful cooperation in the frame of investigations at the Schlema site.

\section{References}

Jansson, P.E. and Karlberg, L. (2012) Coupled heat and mass transfer model for soil-plant-atmosphere systems, Department of Civil and Environmental Engineering, Royal Institute of Technology.

Löser, R., Schneider, P., Meyer, J., Schramm, A. and Gottschalk, N. (2011), Assessment of Uranium Waste Dump Closure Systems: Results of Long Term Test Fields at the former Uranium Mining Site in Schlema-Alberoda, Germany, The New Uranium Mining Boom, Challenge and lessons learned, pp. 663-672.

Löser, R., Bonim, C., Sahm, C. and Schneider, P. (2012) Datenauswertung und Modellabgleich zu Bodenmessplätzen in der Niederlassung Aue 2011, Chemnitz, 107 p.

O'Kane, M., Roscher, M., Barnekow, U. (2011) Hydrology of Soil covers on Mine wastes - Selected Examples of Wismut and International Experiences - Nachhaltigkeit und Langzeitaspekte bei der Sanierung von Uranbergbau- und Aufbereitungsstandorten, Proceedings des Internationalen Bergbausymposiums WISSYM_2011, 2011, pp. 167-185

Schmidt, M. (2010) HELP - Modellrechnung zum wasserhaushaltlichen Verhalten ausgewählter Testfelder der Wismut GmbH am Beispiel der Halde Beerwalde, bachelor thesis, TU Bergakademie Freiberg. 